\title{
A Feminist Defense of the Critical-Logical Model
}

\author{
KATHLEEN MILleR York University
}

Key Words: argument, communication, critical-logical. feminist, world-view.

\begin{abstract}
In his (1994) "Feminism, Argumentation, and Coalescence". Michael Gilbert argues that the "Critical Thinking Industry" is antagonistic to women. Because the critical-logical skills in which the industry deals tend to be gender-specific, its adoption as the dominant mode of discourse disenfranchises women, making its overhaul a moral imperative. Following a variety of feminist epistemologists, this conclusion is reached by conflating "critical reasoning" with "communicating about ideas," as though the two were inseparable. In this paper it is argued that the inclusion of feminist modes of communication and evaluating ideas are not at odds with the Critical-Logical model of reasoning. Rather, the very critical features embedded in the feminist approach would seem to represent the best means of arriving at the truth.
\end{abstract}

In his (1994) "Feminism, Argumentation, and Coalescence," Michael Gilbert examines what he refers to as the "critical reasoning industry." Because the "Critical-Logical" model upon which the industry is premised alienates large numbers of women, feminism suggests to Gilbert a moral imperative: inclusivity, he argues, means abandoning the "critical" approach for one of "coalescence" and this despite the general utility of critical reasoning. This conclusion, I suggest, is necessary only if one conflates values and modes of communication, which tend to be gender-specific, with the business of being critical, which does not. There is nothing in either a feminist epistemological perspective in general, or indeed in any of the information Gilbert brings to bear on his argument in particular, which is at odds with a critical approach to argumentation. Neither is this strictly a moral issue.[1] Rather, the decision to embrace a feminist approach to epistemology would seem to stem directly from the application of these very skills, for in forgoing an epistemology of "finding fault" for one of "increasing understanding," we increase our chances of arriving at the truth.

The concept of truth does not figure significantly in "Feminism, Argumentation, and Coalescence." Instead, Gilbert applies a form of epistemological relativism to the differences between male and female modes of reasoning, contrasting the "critical-logical" approach-which he identifies as predominantly male, with a "coalescent" approach-which he identifies as predominantly female, and argues that the latter ought to be accepted on moral grounds. But because at some points in his argument Gilbert seems to suggest merely supplementing critical-logical skills, and at some points he seems to call for out-and-out abandonment, it is difficult to discern precisely what Gilbert requests of the reasoning industry when he argues that it must be altered to 
accommodate modes of communication peculiar to women. Is he advocating that we abandon critical reasoning in its entirety, or simply that we add something to critical reasoning to make a predominantly male practice more palatable to the rest of the population?

The short answer, I suggest, is that since the Critical-Logical model both defines what it means to be reasonable and explicitly forbids any inference which is inconsistent with this definition, it is difficult to see how it could be expanded to accommodate inferences which are under its rubric unreasonable. Since Gilbert dismisses this approach as unnecessarily restrictive, his position would seem to entail abandoning the entire enterprise, whether or not this is actually what he had in mind. Moreover, because Gilbert presents critical-logical and coalescent positions holistically, as encompassing different "world-views," the two would on his account appear to be incommensurable. Certainly the fact that women are according to Gilbert "not heard," "not understood," and "dismissed from the realms of power in which C-L is the dominant mode" would seem to suggest this.

The fact that women's reasoning is not appreciated, Gilbert contends, leads to systemic discrimination in a world dominated by "men's reason." The decision to abandon the dominant critical-logical mode of discourse is thus a moral one:

If there are significant differences in reasoning modes between some men and some women, and those women's modes are not generally respected, permitted, or heard as freely and easily as the dominant men's, then there must be a moral onus on the part of argumentation theorists, especially in their normative role of argument judges and critical thinking teachers, to see that such modes are incorporated into mainstream teaching, research, and consideration. $^{2}$

Since according to Gilbert the differences between gender-specific modes of reason amount to differences of "world-view," to understand what he is up to here it is necessary to understand the relationship between modes of reasoning and world-view. The two, on his account, are inseparable. This would seem to entail that "world-views" are incommensurable, and indeed Gilbert presents them in a relativistic, epistemically-neutral way:

In the United States the exclusion of religious visions, personal insights or bodily threats from a court of law is a social and political decision based on long historical precedent. In Iran, to cite a different case, religious insight and interpretation play an important role in the courts. The acceptance that one mode of reasoning or proof is better or more reliable is, in the end, a combination of practical, political and moral influences deeply effected by ancient trends in social power and intellectual history. Every society will have a dominant mode, the question is whether it is fair given the precepts and ideals of that society. ${ }^{3}$

Having identified the dominant mode of discourse in our society as "criticallogical," Gilbert asks whether its acceptance is fair, given the precepts and ideals in our society, and finds that it effectively excludes women from power in every area of society: since women do not for the most part communicate in this way, and the critical-logical world view applies in virtually every institution in society, 
women suffer systemic discrimination. "A trial," he notes, "is halted when someone begins to cry, believing without concrete evidence is "childish," (and) emotional reactions are excluded from business decisions."

Because these are, according to Gilbert, the principal means by which women tend to communicate, and they are incompatible with the modes of communication common to the (male) ruling elite, women are bound to be excluded from the upper echelons of power. This strikes Gilbert as unfair. The solution, he suggests, is to change the dominant mode of communication:

The Critical-Logical Model is liable to disenfranchise a significant part of the population with regard to modes and styles of reasoning. The solution is found in coalescent reasoning, an approach to argumentation that focuses on finding agreement rather than emphasizing disagreement and criticism. ${ }^{3}$

Gilbert's argument hinges on the idea that the dominant critical-logical mode of reasoning involves much more than simply a set of rules (formal and informal logic) and guidelines for applying them. The Critical-Logical model must according to him be viewed not as a set of abstractions which formalize the rules of inference irrespective of context or content, but rather as the embodiment of a distinct and specific world-view. An argument, he explains, must be viewed "not as an isolated and autonomous artifact, but as a position-cluster of attitudes, beliefs, feelings, and intuitions." I suggest that this central premise in Gilbert's own argument rests on an equivocal use of the term "world-view". Even if modes of reasoning in different cultures are incommensurable, it does not follow from the fact that the way in which one communicates his/her beliefs in ours tends to differ along gender lines that this difference reflects a comparable difference in world-view. Women's values and modes of communication may well diverge from men's in significant ways. Choosing between them may be a moral problem. But the choice cannot, given Gilbert's own definition, be between "world-views" because on his definition world views are incommensurable. Normative decisions on his account are possible only within paradigms.

Since the differences between women and men which Gilbert presents here are differences of values, they would seem to be quite separable from the criteria he uses to distinguish between epistemological world-views. Indeed, the moral dilemma of choosing between argumentation and coalescence with which he confronts us would seem to be a typical example of the sort of value judgement he identifies as being meaningful only in the sense that its solution is appropriate to achieving the ends of the particular paradigm under consideration. This point becomes clear when one considers the way in which the values which shape our ethical "world-view" have undergone considerable upheaval, while the rules of inference and evidence which constitute our epistemological "world-view" have not.

To use Gilbert's example, a woman's inclination to cry in court might represent an emotional display somewhat out of keeping with the solemnity of the situation in the sense that it is not politically correct to cry in public. But this would seem to be something quite separate from her acceptance of the logic 
behind the rules of evidence, reasoning, proof, liberty-and-justice-for-all, and similar "world-view" indicators in which that court is situated. Note that the reversal of this ethic-every presidential candidate in America is, for example, now unofficially required to cry at least once during the course of his campaignbears neither on the general perception of his intellectual abilities, nor on the requirement for rationality in office. It has nothing to do with whether or not he will be "heard." It simply reflects the evolution of attitudes about what constitutes a 'real man.' These days, it seems, toughness is out, sensitivity and understanding, in. Similarly, if part of the population values sensitivity and understanding in the appraisal of intellectual ideas, it is quite possible to effect the evolution of these values within a world-view based upon the rules of logic, reason, and critical thinking. Argument-as premises and conclusion-is indispensable to the critical-logical world-view; argument-as fault-finding debate- - is inappropriate to its ends.

Following a variety of feminist epistemologists, Gilbert conflates the two, concluding that it is the Critical-Logical model itself which is at fault. By keeping them separate, it is quite possible to combine the arguments (as "isolated artifacts") inherent in the Critical-Logical model with the very coalescent approach to argumentation (as "communicating one's beliefs") he endorses. It is also possible to interpret what Gilbert identifies as the two central features of the coalescent approach-considering the "situation" of the individual making a claim, and the emphasis upon seeking agreement-as epistemological rather than moral imperatives. Indeed each of these would seem to be absolutely indispensable if we are to be truly critical. Coalescent reasoning, I will argue, is not only consistent with the Critical-Logical model; it is the best method of applying its dictates.

Taking as a point of departure the acceptance of gender-specific values and modes of communication, Gilbert argues that inherent in the entrenchment of an understanding-based feminist epistemology is a moving-away from criticismbased skills like "analysis," "finding errors in reasoning and logic," "identification of fallacies (and) grounds for accepting or rejecting an argument." Yet he also acknowledges just how useful such skills are, pointing out that critical reasoning courses are of enormous and immediate benefit to students-both in their other academic courses and in all professional fields.

"(T)he teaching of critical thinking," Gilbert concedes, "is a large industry with an eager and generally satisfied consumer audience":"

The ability to examine an argument critically, find its faults and flaws remains a skill that (a student) can apply across the board. They can, after all. begin immediately by using it in their other courses, and the many who make that magical connection do so and keep doing so. In short, they acquire a whole approach to reasoning and thinking that they find very successful. This is especially true in their current academic environment and later in the industries it feeds, primarily business and government. ${ }^{10}$ 
He also makes it clear that the logical relationships-both formal and informal-in which the industry deals are in themselves beyond reproach." Why then, would he urge us to dispense with, or even downplay, the teaching of critical skills?

In the tradition of feminist epistemology, Gilbert arrives at this conclusion by conflating critical skills, which are epistemically 'neuter', with aggressive modes of communication, which tend to be male-orientated. The fact that both are deeply embedded in both the philosophical tradition in particular and Western culture in general seems to suggest that they are inseparable. But in fact they are two very different things, as indeed the bulk of the sociological information he brings to bear on the problem would seem to confirm, describing as it does the differences between women and men's ethical world-views.

Gilbert begins by presenting what he refers to as the "Critical-Logical Model" ("C-L" for short) in which traditional philosophy is steeped. Because it reflects a male-oriented view of reality, the values which characterize this model tend to emerge in sharp dichotomies: the "true/false" dichotomy, the "convince/persuade" dichotomy, the "Natural Light" theory. ${ }^{2}$

Committing to neither a "nature" nor a "nurture" position regarding how they got that way, Gilbert contrasts this (male) C-L model with a female-oriented system of values which he derives from a variety of feminist literature, ${ }^{13}$ offering a number of telling sociological facts about the differences between the way women and men communicate and confront the world. These studies show that women "communicate differently than men, hold different values than men, and prioritize differently than men." ${ }^{\prime 4}$ Women, they claim, have a conceptual framework of "connectedness," in which community, relationships, understanding, and acceptance are of paramount importance..$^{\text {s }}$

Men, in contrast, tend to have a conceptual framework of "separateness," in which independence, competition, and aggression rule. The result is that women and men act very differently, even in childhood:

One concrete difference in the approach to argumentation can be seen when we examine the ways in which the boys and girls Gilligan studied play. Boys have no compunction about having raging arguments concerning rule violations or judgement calls involving intense, often legalistic argument, shouting, name-calling, accusations, threats, and recriminations. Very importantly, however, the game does not stop, while for the girls, on the other hand, a quarrel often means the end of the game. Gilligan interprets this as meaning that to the girls the rules are just not as important as the feelings of the players .... The connection to argumentation and critical thinking is obvious. When we teach the Critical-Logical Model we are very rule focused. The emphasis is on what is said and how to analyze the words. On the C-L model it is the words and the rules that are paramount, not the partners in the dispute. The feminist model, on the other hand, denies the separability of persons, rules, words, and positions. ${ }^{15}$

According to Gilbert's sources, such differences between women and men abound in our society. Women of every age tend to foster relationships of caring, 
understanding, and sympathy, while men strive to assert their independence through domination and control of others:

Women are far more focused on their attachments to others, their place in the web of human relationships, and their connectedness to the people with whom they interact. Men, on the other hand, have independence from others, their status in the hierarchy of individuals, and their separation from control and obligation as paramount loci. ${ }^{17}$

It must be pointed out that these playground scenarios would seem to be open to a variety of alternative interpretations, not all of which would construe the girls' behavior in so charitable a light. ${ }^{\prime 8}$ But if these examples are problematic in the sense that there would seem to be considerable bias in the way which they extoll the virtues of female modes of communication and values while vilifying men's ("independence", for example, is not synonymous with "control," which can be exercised every bit as effectively through weakness and dependence), they are nevertheless useful in their identification of the sorts of values that the philosophical community stands to benefit by adopting. It is the inference from differences in values to differences in reason which is questionable. For note that these sociological reports about the way girls play and women nurture while boys fight and men compete and conquer are advanced not as psychological or ethical, but epistemological indicators: "The connection to argumentation", Gilbert maintains, "is not tenuous, but concrete."

If the critical-logical world view is based upon formal modes of argument, in other words, this must be because men dominate in our society, and men tend to relish a good brisk battle:

Just like the tumult of wrestling and tackling, arguing can be very aggressive, and apparently antagonistic, but also exhilarating and downright enjoyable to those to whom it is considered play, ${ }^{20}$

Because aggression of this sort tends to alienate women, and does nothing to advance the quest for truth. Gilbert rightly advocates its abandonment. Surely, a feminist approach to argumentation would be both kinder to all and more appropriate to the ends of intellectual endeavor. Men could compete on the squash court; women could nurture wherever; and we could all get together and try to understand instead of divide and conquer each other in the academic arena. This, I take it, is a "feminist" perspective. But the perspective to which Gilbert appeals seems not to appreciate the fact that a communication of understanding is not exclusive of the epistemological goals embedded in the Critical-Logical model. It doesn't follow from the fact that women's communication tends to reflect understanding, and men's, aggression, that the latter's critical orientation is also at fault. Rather, it is that a rigorously critical approach combined with an ethics of "trying to understand," as opposed to "attacking for sport," would seem to be the best means of arriving at the truth.

It must be noted that much of our critical reasoning is not combined with discussion of any sort. Critical reasoning courses teach students to evaluate the arguments implicit in all manner of information, from the evening news to 
advertisements to text-book analysis. None of this generally involves discussion or debate. The situation differs somewhat in the academic arena, but here too decisions are formulated and evaluated largely in isolation. The presentation of one's ideas, and reception of another's, is where the issue of "understanding" vs. "attack" come in, but the acceptance or rejection of a particular opinion results from the straightforward application of critical reasoning, even for a feminist epistemologist. To illustrate, I will use an example from my own area of study. Consider an epistemological appraisal of the current situation in the medical sciences, a problem of vital concern in both scientific and political domains.

There is currently considerable debate-among individuals, in government, and within the medical community itself-concerning the kind of health care system which would be "best." The decision amounts to choosing between traditional invasive techniques (i.e. surgery and chemotherapy) and an holistic, preventative approach. The traditional approach is authoritarian and largely insensitive to the causes of illness. In traditional medicine, when one falls ill he "puts himself under a doctor's care," much as he might put his tax returns under an accountant's care. The doctor makes a diagnosis, prescribes a course of treatment, and, if she is successful, "heals the patient." Based as it is on a preventative model, holistic medicine is more concerned to "promote wellness" than to heal sickness, so the holistic physician takes an entirely different approach. Her job begins not when the patient is ill, but when he is well. Her primary concern, then, is to keep him well, rather than to "heal" him.

But should the patient happen to fall ill, the holistic approach to healing is also different. In the holistic model, the health care professional facilitates the healing process, but it is the patient who is said to "heal himself". He does this by educating himself about the causes of his condition and participating in the decision as to the most appropriate treatment-taking, in other words, responsibility for his own health, rather than simply handing it over to the doctor. The treatment, too, is different in the holistic model, which employs clinical, as well as laboratory diagnostic techniques, promotes natural alternatives to drugs and surgery, and emphasizes such things as nutritional and life-style factors not addressed by traditional medicine.

The two approaches are in many ways diametrically opposed, and the debate is often bitter, with traditional physicians claiming to be "scientists", as opposed to "crackpots," and holistic physicians claiming to be empathetic and enlightened, as opposed to autocratic and narrow-minded. This, of course, is just the male mode of argumentation all over again, and it is not especially helpful. Yet the problem remains a compelling one, both on political and personal levels. So how does one decide between the two?

A proper epistemological appraisal will be critical of both approaches. It will be concerned to understand the context in which each view is "situated," and to find points of agreement between it and other truths. The theoretical underpinnings of a position-even a scientific one-are not separable from, but 
rather representative of, an underlying metaphysics and set of values which must be taken into consideration along with a variety of sociological factors. Where, for example, does each respective physician get her information, and what is her perspective on human nature?

If it turns out that the traditional physician gets her information primarily from research funded by large pharmaceutical companies, then this fact will be relevant to the decision. If it turns out that the traditional physician believes that people in general are, or ought to be, completely dependent upon their doctor and largely ignorant about the disease which afflicts them, then this will also be relevant. An anthropological survey of medical practices may well uncover useful information about the myriad ways in which a body can heal, as may a survey of possible psychological and sociological components to health. Even the financial component cannot be disregarded. Does the physician receive a salary for general care, or does she have a fee-for-service payscale? Do intuition and personal experience enter into all of this? Answer: sometimes they do. One's intuitions about human autonomy, for example, might well reflect a deeplyrooted conflict with the metaphysical presuppositions of a particular position, and ought not to be dismissed as irrelevant. Intuitions aren't decisive, for it is of course necessary to expose and analyze the conflict, but they ought not to be ignored. The entire business of pitting reason against intuition can, following Bailin, be shown to be based on a "false dichotomy between reasoning and creative thinking ... and a false opposition between reason and emotion":

There are not two distinctive and opposite kinds of processes of thinking, one kind irrational and leading to creative achievement and the other kind rational and involved in the evaluation of ideas or products. Rather, there are analytic, highly judgemental aspects to generating creative results and imaginative, inventive aspects to logic and reasoning and it is exceedingly difficult to separate out two distinct and opposite kinds of thought. ${ }^{20}$

Note that taking all of the above into consideration is "coalescent" in that it contains the two key elements of feminist reasoning: a recognition of the "situation" of the person supporting a particular decision, and an emphasis upon agreement with other accepted truths. But note also that there is nothing in such an appraisal that is anything less than rigorously critical and logical. Indeed, it is difficult to imagine how an adequate epistemological appraisal could omit any of these components and still be "critical-logical." The critical-logical model, then, is not antagonistic to feminist epistemology, but if the preceding argument has any weight at all, feminist epistemology properly construed is the very embodiment of the critical-logical approach.

\section{Notes}

' I would like to thank Michael Gilbert for his comments and clarifications, and Richard Reiner, co-ordinator of the International Philosophical Pre-print Exchange. for making Professor Gilbert's paper available to me. 
Gilbert would agree that this is not exclusively a moral issue. Although the paper under consideration focuses on the moral aspects of the problem, he did in a discussion with me indicate that he is also committed to the epistemological superiority of feminist argumentation.

${ }^{2}$ p. 9.

${ }^{3}$ p. 7.

${ }^{4}$ p. 6.

s.p. 1 .

${ }^{6}$ p. 4.

${ }^{7}$ For a critique of epistemological relativism see Seigel (1987).

s. 1.

p. 1.

${ }^{10}$ p. 2.

"1) 22.

${ }^{12}$ The theory that "the 'true' or 'best' position will be the one to survive a properly conducted rational competitive inquiry." (pp. 1-2.)

${ }^{13}$ Code (1991); Gilligan (1982); Hawkesworth (1987); Lakoff (1990); Leggee (1992): Nye (1990); Perelman (1969); Tannen (1984, 1990).

${ }^{14}$ p. 4.

${ }^{15}$ Gilligan (1982).

${ }^{16}$ p. 9

17 p. 11 .

${ }^{18}$ Many women familiar with the sorts of games girls play will remember looking with longing at the "male model," which made it possible to get through an entire game without hurting anyone's feelings.

${ }^{14}$ p. 11 .

${ }^{20} \mathrm{p} .14$.

${ }^{21}$ Bailin (1992), p. 40.

\section{References}

Code. Lorraine. 1991. What can she know? Ithaca: Cornell University Press.

Gilbert. Michael. 1994. "Feminism. Argumentation and Coalescence." Injormal Logic 1695 113.

Bailin, Sharon. 1992. "Rationality and Intuition," in Reason and values: new essays in philosophy of education. Iohn Portelli and Sharon Bailin. eds. Calgary: Detselig Enterprises.

Gilligan, Carol. 1982. In a different voice. Harvard: Cambridge.

Hawkesworth, Mary. 1987. "Feminist epistemology: A survey of the field", Women and Politics 7:13 115-127.

Lakoff, Robin. 1990. Taking power: The politics of language. Basic Books: New York.

Legge, Nancy. 1992. "WWat Did You Mean by That"? The function of perceptions in interpersonal argument". Argumentation and Advocacy 29:2 41-60.

Nye, Andrea. 1990. Words of power. Routledge: New York.

Perelman, Ch., and Olbrechts-Tyteca. L. (1969). The new rhetoric. Notre Dame. Indiana: University of Notre Dame Press. 
Seigel, Harvey. 1987. Relativism refuted. Dordrecht: D. Reidel.

Tannen, Deborah. 1984. Conversational style: Analyzing talk among friends. Ablex: Norwood, New Jersey.

Tannen, Deborah. 1990. You just don't understand. New York: Ballantine Books.

KATHLEEN MILLER
DEPARTMENT OF PHILOSOPHY
YORK UNIVERSITY
4700 KEELE STREET
NORTH YORK, ONTARIO MSJ IP3
$\square$

